\title{
Good Times - Bad Times: My Story regarding Acute Stroke Treatment
}

\author{
Werner Hacke \\ Neurologische Klinik, Universität Heidelberg, Heidelberg, Germany
}

\section{Introduction}

This will be a biased, noncomprehensive and egocentric essay. The request by Michael Hennerici and the European Stroke Conference committee was to present an overview of my career in stroke and what the disappointments and highlights had been over the past 25 years. Many of the developments that I will describe were not unique to the places where I worked. In contrast, similar activities were undertaken in other parts of the world, mostly the USA, Japan and Australia (examples: thrombolysis trials and imaging-based patient selection), but we were involved quite early and we were lucky enough to publish a few important and highly cited papers.

To describe my route in the field of acute stroke treatment and critical care of stroke, I have to start quite early. In 1975, after almost 3 years of training in psychiatry, I entered the Department of Neurology at the RWTH Aachen Medical School. It was the right place and I met the right people. My teachers there were the late Klaus Poeck, a very renowned neuropsychologist (but also interested in stroke), and Hermann Zeumer, a neurologist who was just busy to get his board certification in radiology. He was the person who did most of the neuroradiological work in the hospital and the genius who had many of the good ideas that we will talk about. After 2 years of

\section{KARGER}

(c) 2013 S. Karger AG, Base

1015-9770/13/0364-0257\$38.00/0

E-Mail karger@karger.com

www.karger.com/ced training, a vacancy on the neurological intensive care unit (ICU; 6 beds neurology only) opened up.

And here the story begins.

\section{The Aachen Days 1979-1987: The Reinvention of Thrombolysis}

In precomputerized tomography (CT) times, several attempts had been made to use thrombolysis in stroke patients. In most cases these were very late, desperate attempts in severely affected patients, in whom it was unclear whether the patient had ischemic or hemorrhagic stroke. Many patients died, and upon autopsy, massive hemorrhages were found and thrombolysis was thereafter abandoned.

Modern thrombolysis in the imaging age started with a series of young basilar artery thrombosis patients admitted to our ICU, who all died. We were very much moved by these tragedies. Hermann Zeumer, who had introduced transfemoral cerebral angiography into our neuroradiology services, contacted our cardiologists (who were using intracoronary streptokinase) and borrowed some wires and catheters. The next patient came: a young lady who had her basilar occlusion during exercise (now we know it was a spontaneous vertebral dissec- 
tion, at that time completely unknown to us). I admitted her to the ICU. We asked our chairman Klaus Poeck whether we were allowed to give intra-arterial thrombolysis a try. He agreed and Hermann did it. He managed to advance a catheter into the left distal vertebral artery and infused 320,000 IU of streptokinase. During the procedure, progressive recanalization was documented. At the end, the basilar and both posterior cerebral arteries were open. The next day the patient was extubated and she went home a couple of days later with what we nowadays would call a modified Rankin scale (mRS) of 1 .

This was an important event for the future stroke neurology and the beginning of modern thrombolysis, and I was a proud witness, although I had no idea how much this would influence my career. Our excitement got a major hit when a leading journal rejected our case report (that was later published in German [1]), by calling it an unethical approach that should not be further tested. Two years later, our first 4 patients were presented in the American Journal of Neuroradiology [2]. In the meantime Hermann had also successfully reopened distal internal carotid artery (ICA) and middle cerebral artery (MCA) occlusions [3], and it seemed to us that recanalization was associated with better than expected outcome (an end point that even 30 years later is still the best available evidence for transvascular procedures).

Our activities did not remain unnoticed. Groups in San Diego, Cleveland, Boston and Osaka entered the field, and we started a close collaboration with the Scripps research foundation in La Jolla, Calif., USA. Greg Del Zoppo came to Aachen for a year, and thereafter Bernd Ringelstein and I went to California. The cooperation generated 3 important papers that all became highly cited early pieces of the evolving literature on thrombolysis.

The first paper presented a series of 43 consecutive patients with severe brainstem stroke and angiographically demonstrated basilar artery occlusion published in Stroke in 1988 [4]. In this nonrandomized retrospective study the patients received local intra-arterial thrombolysis (urokinase or streptokinase). We looked at the role of occlusion sites, response to therapy and clinical outcome. Recanalization after thrombolysis was linked with clinical outcome. No patients without recanalization but 14 of the 19 patients with recanalization survived, 10 of them with what we then called a favorable outcome. We concluded that technically successful thrombolysis of basilar artery occlusions is associated with beneficial clinical outcome.
In the same year we published the first larger MCA series [5] that included patients from Aachen, Germany, and La Jolla, Calif., USA. This was a prospective uncontrolled angiography-based pilot study reporting the results of 20 patients with acute (mean onset treatment interval $7.6 \mathrm{~h}$ ) MCA stroke. Fifteen of 20 patients achieved complete recanalization with 10 of them showing a favorable outcome at the time of discharge. We observed asymptomatic hemorrhagic complications in 4 patients. We concluded that recanalization of carotid territory arterial occlusions may be achieved with intra-arterial fibrinolytic agents and may be associated with beneficial clinical outcome.

While still in Aachen we started also our first approaches to intravenous thrombolysis [6]: in a transatlantic open angiography-based, dose rate escalation study we examined the effect of intravenous recombinant tissue plasminogen activator (rt-PA) on recanalization in patients with acute ischemic stroke (AIS). After the 60-min rt-PA infusion, arterial perfusion was assessed by repeat angiography. Follow-up CT scans were performed at $24 \mathrm{~h}$ to assess hemorrhagic transformation. We included 139 patients. About $80 \%$ had complete vessel occlusion. No dose response was observed in the 93 patients who completed treatment. Occluded distal MCA (M2 and M3) branch occlusions were more likely to recanalize. Symptomatic hemorrhage (sICH) occurred in $10 \%$ of the treated patients. This study showed that site of occlusion and time to recanalization were important variables in intravenous thrombolysis.

\section{7 until 2000: The Early Heidelberg Days - Thrombolysis, Malignant MCA and the First Large Randomized Trials}

The year 1987 marked the most important step in my clinical and scientific career. After almost 1 year in California I moved to Heidelberg to take the chair of the Department of Neurology at the University of Heidelberg. When I started, the department had just moved into a brand-new hospital with a 12-bed Neurology ICU. Neuroradiology was part of the Neurological Institute, but we soon managed to elect Klaus Sartor as Professor and Chair of this department which evolved into one of the most influential institutions in Germany. Many wellknown leaders in the field of cerebrovascular neurosciences were trained in Heidelberg and continued their successful careers elsewhere.

The work in Heidelberg was always characterized by a close collaboration between Neurology, Neurosurgery 
and Neuroradiology. This is also reflected in the 3 main AIS topics that we worked on over the next 25 years: thrombolysis, hemicraniectomy and imaging-based patient selection. I will not describe our activities in the field of intracerebral hemorrhages, general neurocritical care, prevention and others.

\section{Thrombolysis}

The first major paper from Heidelberg was coauthored by Rüdiger von Kummer, an excellent neurologist who later turned into an outstanding neuroradiologist famous for coining the CT criteria of early infarction. We performed a prospective open trial of high-dose intravenous rt-PA in combination with heparin anticoagulation in AIS [7].

Thirty-two patients with angiographically proven MCA and/or intracranial ICA occlusion were treated with $100 \mathrm{mg}$ i.v. alteplase over $90 \mathrm{~min}$ within $4 \mathrm{~h}$ after symptom onset. Recanalization was assessed immediately after treatment and in a few patients also at $24 \mathrm{~h}$. We observed early (90 $\mathrm{min}$ ) complete or partial reperfusion in $34 \%$ of the patients and in $53 \%$ within $12-24 \mathrm{~h}$. Fatal parenchymal hemorrhage occurred in 3 severely affected patients. Good clinical outcome was associated with the presence of collateral blood flow $(\mathrm{p}<0.01)$ and reperfusion $(\mathrm{p}<0.05)$.

The next step was towards randomized clinical trials (RCTs). Together with my coinvestigators Cesare Fieschi from Rome, Italy, and Markku Kaste, Helsinki, Finland, the first European Collaborative Acute Stroke Study (ECASS) was designed. We had an illustrious international steering committee who all contributed to the paper that was published as the first large rt-PA RCT in the Journal of the American Medical Association in 1995 [8].

ECASS was a double-blind RCT comparing rt-PA treatment with $1.1 \mathrm{mg} / \mathrm{kg}$ body weight to placebo within $6 \mathrm{~h}$ from the onset of symptoms. A total of 620 patients with moderate to severe hemispheric AIS were included. Until ECASS only early hemorrhage was used as exclusion. We added early major infarct signs to the CT exclusion, a new concept which was based on work by Rüdiger von Kummer. A good concept, but it created some problems in the participating centers because of its novelty.

We had 2 coprimary end points, which were not a good choice: neither in the median of the mRS nor in the median of the Barthel index (BI) did we have significant results in the intent-to-treat (ITT) analyses, mostly because of inclusion of more than $50 \mathrm{CT}$ exclusion violators. Safety parameters included mortality and incidence of intracranial or extracranial hemorrhage.

Good Times - Bad Times: My Story

regarding Acute Stroke Treatment
The target population (TP) analysis showed a significant difference in the $\mathrm{mRS}$ in favor of rt-PA-treated patients $(\mathrm{p}=0.035)$. Off the secondary end points, the combined BI and RS showed a difference in favor of rt-PAtreated patients in ITT and TP $(\mathrm{p}<0.001)$. Neurological recovery at 90 days was significantly better for rt-PAtreated patients in the TP $(\mathrm{p}=0.03)$. In-hospital stay was significantly shorter in the rt-PA treatment arm in both analyses. There were no statistically significant differences in the mortality rate at 30 days or in the overall incidence of ICHs among the rt-PA and placebo treatment arms in either analysis. However, the occurrence of large parenchymal hemorrhages was significantly more frequent in the rt-PA-treated patients. ECASS, by the way, also created the definitions of hemorrhagic infarctions (HI 1 and 2) and parenchymal hemorrhages ( $\mathrm{PH} 1$ and 2 ), which, with some modifications, are still used in most antithrombotic stroke trials.

We concluded: 'Intravenous thrombolysis in acute ischemic stroke is effective in improving some functional measures and neurologic outcome in a defined subgroup of stroke patients with moderate to severe neurologic deficit and without extended infarct signs on the initial CT scan. However, the identification of this subgroup is difficult and depends on recognition of early major CT signs of early infarction. Therefore, since treating ineligible patients is associated with an unacceptable increase of hemorrhagic complications and death, intravenous thrombolysis cannot currently be recommended for use in an unselected population of acute ischemic stroke patients' [8].

A little later that year, the results of the NINDS rt-PA trial were presented and published [9]: the study included 624 patients with ischemic stroke treated intravenously with either placebo or rt-PA $(0.9 \mathrm{mg} / \mathrm{kg}$, maximum $90 \mathrm{mg}$ ) within $3 \mathrm{~h}$ of symptom onset. The study used a much more useful end point (global end point analysis) and was significant. Favorable outcome (complete or nearly complete neurological recovery 3 months after stroke) was achieved in $31-50 \%$ of patients treated with rt-PA compared to $20-38 \%$ of patients given placebo.

In 1996 the US Food and Drug Administration approved the use of intravenous rt-PA as treatment for acute ischemic stroke in a 3-hour time window after symptom onset based on the results of the NINDS rt-PA Stroke Study.

Based on these results we performed a retrospective analysis of the ECASS ITT data set (615 randomized and treated patients, rt-PA treatment vs. placebo) and adopted the NINDS trial statistical methodology [10]. The 
global end point statistics showed a significant increase ( $\mathrm{p}=0.008$; odds ratio, OR, $1.5 ; 95 \%$ confidence interval, CI, 1.1-2.0) of favorable outcome in the rt-PA-treated patient group. The difference was also statistically significant for the mRS 0.1 ( $\mathrm{p}=0.044$; OR 1.4; 95\% CI 1.0-2.0). In fact, had we chosen a better end point or had we trained our investigators better in reading early CT scans, ECASS would have been positive, but it was not.

In ECASS II [11], we assessed the safety and efficacy of intravenous rt-PA at a lower dose $(0.9 \mathrm{mg} / \mathrm{kg}$ body weight $)$ within $6 \mathrm{~h}$ of stroke onset. ECASS II was a nonangiographic, double-blind RCT that enrolled 800 patients in Europe, Australia, and New Zealand. We used the ECASS $\mathrm{CT}$ exclusions again and performed a mandatory CT training. The primary end point was the mRS at 90 days, dichotomized for favorable (score 0-1) and unfavorable (score 2-6) outcome.

We found a $3.7 \%$ absolute difference in the primary end point $(\mathrm{p}=0.277)$. In a post hoc analysis of the $0-2$ mRS dichotomy, the absolute difference was $8.3 \%$ ( $\mathrm{p}=$ 0.024 ). Again, our results did not confirm a statistical benefit for alteplase. We had the wrong end point, again. By the way, the shift analysis, which was not yet known at that time, was positive for ECASS and ECASS II.

\section{Critical Care and the Malignant MCA Infarction}

With the increasing activities in hyperacute stroke treatment, we became aware of the fact that herniation due to massive MCA or hemispheric infarction was not as rare as many had believed. In fact, in ECASS the most frequent cause of early neurological death was herniation due to edema, not hemorrhage [8].

Together with Stefan Schwab, Michael DiGeorgia, Derk Krieger and others we studied the clinical course of 55 patients with complete MCA infarction, defined by CT and vascular imaging [12]. Serial CTs with measurement of midline shift, septum pellucidum shift and vessel status were obtained directly after admission. All patients had embolic infarction. Their mean age was 50 years. Fortynine patients required ventilator assistance during the acute stage of disease. Only 12 patients (22\%) survived the infarct. The cause of death was transtentorial herniation with subsequent brain death in 43 patients.

We concluded that the prognosis of complete MCA stroke is very poor ('malignant') with an almost $80 \%$ inhospital mortality and can be predicted by early clinical and neuroradiological data within the first few hours after the onset of symptoms. We described the typical clinical course of malignant MCA infarction which starts with an early impaired level of consciousness, followed by a pro- gressive deterioration over the next 24-48 h finally leading to midline shift and herniation.

This clinical description had been submitted in 1994, but was published as late as 1996, mostly because some reviewer did not believe that this condition exists. Therefore the first intervention series by Klaus Rieke, Stefan Schwab, Derk Krieger, Alfred Aschoff, and Volker Schuchardt was published [13] before the clinical description finally appeared [12]. At the same time Michael Forsting and Arndt Doerffler published their experimental decompression study in rats [14].

Klaus Rieke's study described a prospective, consecutive nonrandomized patient group undergoing decompressive surgery for malignant MCA infarction with a control group derived from the clinical paper [12]. Outcome was rated at discharge from the hospital (Glasgow Outcome Scale) and at follow-up (BI, Oxford Handicap Scale).

Thirty-two patients recruited over 3 years were prospectively selected for surgical treatment with extended craniotomy and dura patch enlargement. The mortality of the 32 surgically treated patients was $34.4 \%$ compared with $76.2 \%$ in the 21 conservatively treated patients. The Oxford Handicap Scale indicated no handicap in 1 patient, moderate handicap in 15 patients, and moderately severe handicap in 5 patients with surgery. We concluded that hemicraniotomy might improve survival in massive hemispheric stroke victims by decreasing mortality rates to $<35 \%$. The disability rate remained high (24\%), although some patients seem to benefit significantly.

This finding was confirmed in the second prospective decompressive surgery series, published by Stefan Schwab, Thorsten Steiner and others in 1998 [15]. In this open, prospective study hemicraniectomy was performed in 63 patients with acute complete MCA infarction. About half of the patients were treated within $24 \mathrm{~h}$ after stroke onset. Forty-six patients (73\%) survived. Despite complete hemispheric infarction, no survivor suffered from complete hemiplegia or was permanently wheelchair bound. In 31 patients with early decompressive surgery, mortality was $16 \%$. Early hemicraniectomy led to a significant reduction in the length of time critical care therapy was needed ( 7.4 vs. 13.3 days, $\mathrm{p}<0.05$ ).

We concluded that the outcome of patients treated with craniectomy in severe ischemic hemispheric infarction was surprisingly good and that early decompressive surgery may further improve outcome.

Stefan Schwab also led the first hypothermia in severe stroke trial [16] in 25 patients for therapy of postischemic 
Fig. 1. Time dependency of the rt-PA treatment effect. Modified from Hacke et al. [17].

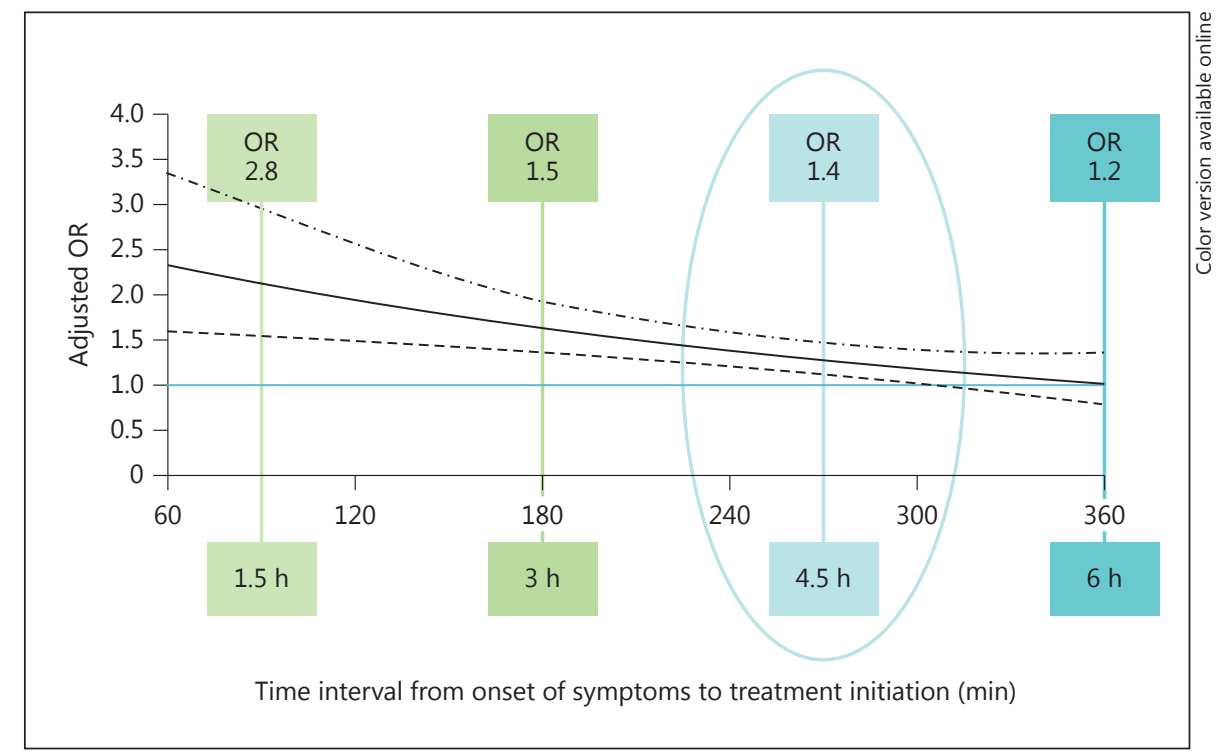

brain edema. Hypothermia was induced within $14 \pm 7 \mathrm{~h}$ after stroke onset and achieved by external cooling. Patients were kept at $33^{\circ} \mathrm{C}$ body core temperature for 48 $72 \mathrm{~h}$. Intracranial pressure (ICP), cerebral perfusion pressure, and brain temperature were monitored continuously.

Fourteen patients survived the hemispheric stroke (56\%). During hypothermia, elevated ICP values could be significantly reduced. Herniation caused by a secondary rise in ICP after rewarming was the cause of death in several patients.

We concluded that moderate hypothermia can help to control critically elevated ICP values in severe space-occupying edema after MCA stroke and may improve clinical outcome in these patients.

\section{Modern Times 2001-2013: Pooled Analyses and Pivotal Trials}

\section{Thrombolysis}

In a joint effort of rt-PA trial investigators including Jeff Donnan, Steve Davis, Tom Brott, John Marler, the ECASS investigators, and others, we pooled data of 2,775 patients from 6 intravenous rt-PA RCTs [17]. Using multivariable logistic regression we assessed the relation of the interval from stroke onset to treatment (OTT) with favorable 3-month outcome and the occurrence of clinically relevant parenchymal hemorrhage.

The median age was 68 years, the median baseline $\mathrm{Na}$ tional Institute of Health Stroke Scale (NIHSS) 11, and the median OTT $243 \mathrm{~min}$. Odds of a favorable 3-month outcome increased as OTT decreased $(\mathrm{p}=0.005)$. Odds were 2.8 (95\% CI 1.8-4.5) for 0-90 $\mathrm{min}, 1.5(1.1-2.2)$ for 91-180 min, $1.4(1.1-1.9)$ for 181-270 min, and $1.2(0.9-$ 1.5) for 271-360 min in favor of the rt-PA group. Hemorrhage was seen in $82(5.9 \%)$ rt-PA patients and $15(1.1 \%)$ controls $(\mathrm{p}<0.0001)$. Hemorrhage was not associated with OTT but was with rt-PA treatment $(\mathrm{p}=0.0001)$ and age $(\mathrm{p}=0.0002)$. The analysis generated a figure (fig. 1$)$ that was subsequently shown in almost every thrombolysis-related presentation, until the updated pooled analysis [18] including ECASS 3 and EPITHET created a new graph not too much different from the original one. The pooled analysis clearly underlined that the sooner rt-PA is given to stroke patients, the greater the benefit and that there may be a potential benefit up to $4.5 \mathrm{~h}$.

\section{ECASS 3}

While rt-PA has been approved in North America since 1996, there was only a conditional approval in Germany and some parts of Europe (although many stroke centers used it off label). The European authorities requested a large registry and a further RCT. As it was considered unethical to perform another sub-3-hour trial, the 3- to 4.5-hour time window was tested in ECASS 3 [19]. We randomized 821 patients (418 rt-PA and 403 placebo). More patients had a favorable outcome (mRS $0-2$ ) with rt-PA (52.4 vs. $45.2 \%$; OR 1.34 ; $95 \%$ CI $1.02-$ $1.76 ; \mathrm{p}=0.04)$. The shift analysis was also significantly in favor of rt-PA treatment. The incidence of intracranial 
hemorrhage was higher with alteplase than with placebo but numerically low ( $\mathrm{sICH}, 2.4$ vs. $0.2 \%$; $\mathrm{p}=0.008$ ). Mortality was also low and did not differ between the groups. Subsequently the time window for thrombolysis was extended to $4.5 \mathrm{~h}$ in Europe and other parts of the world but not in the USA. However, having a longer time window does not mean that the doctors should take more time.

\section{Updated Pooled Analysis}

We added data from ECASS 3 (821 patients) and EPITHET (100 patients) to the data of the first pooled analysis (a total of 3,670 patients treated up to $6 \mathrm{~h}$ ). Kennedy Lees and most colleagues from the 2004 analysis led this effort [17]. We used multivariate logistic regression to assess the effect of OTT with treatment on favorable 3 -month outcome (defined as mRS $0-1$ ), mortality, and occurrence and outcome of clinically relevant parenchymal hemorrhage.

Odds of a favorable 3-month outcome increased as OTT decreased over time $(p=0.0269)$ and no benefit of alteplase treatment was seen after $270 \mathrm{~min}$. Adjusted odds of a favorable 3-month outcome were 2.55 (95\% CI 1.444.52) for 0-90 $\mathrm{min}, 1.64(1.12-2.40)$ for $91-180 \mathrm{~min}, 1.34$ (1.06-1.68) for 181-270 $\mathrm{min}$, and $1.22(0.92-1.61)$ for 271-360 min in favor of the alteplase group. Large parenchymal hemorrhage was seen in $96(5.2 \%)$ of 1,850 patients assigned to alteplase and $18(1.0 \%)$ of 1,820 controls, with no clear relation to OTT $(\mathrm{p}=0.4140)$. Adjusted odds of mortality increased with OTT $(\mathrm{p}=0.0444)$ and were almost significantly increased (1.49; 95\% CI 1.00 2.21) for 271-360 min. Our interpretation was not much different from the previous analysis: patients with AIS benefit from intravenous alteplase when treated up to $4.5 \mathrm{~h}$. To maximize benefit every effort should be taken to shorten the delay in initiation of treatment. Beyond $4.5 \mathrm{~h}$, risk might outweigh benefit.

\section{Desmoteplase and Imaging-Based Selection}

Imaging-based selection is intimately linked to thrombolysis but will be discussed separately.

Together with Olaf Jansen, Peter Schellinger, Jochen Fiebach and Klaus Sartor we published one of the first reports on diffusion-perfusion magnetic resonance imaging (MRI) mismatch as early as 1999 [20]. The rationale for this study was that new MRI techniques of diffusion-weighted imaging and perfusion imaging had been shown both experimentally and in patient studies to reliably detect and define ischemic regions of the brain. For clinical practice it was assumed that diffusion-weighted imaging would show irreversibly injured tissue, whereas perfusion imaging would show the area of reduced cerebral perfusion. The mismatch between these areas was assumed to represent the tissue at risk. We performed a study correlating early MRI findings with morphological and clinical outcome depending on early recanalization. We reported 21 patients with a considerable mismatch (perfusion imaging/diffusion-weighted imaging $>1.2$ ). All had an occlusion of a main cerebral artery (ICA or $\mathrm{MCA}$ ). Eleven patients received rt-PA, 5 of them outside the 3-hour time window. Recanalization was shown in $8 / 21$ patients. We looked at these results as supporting evidence for the mismatch hypothesis and as a chance to use MRI information to initiate thrombolysis outside the approved time window. Like many others, we believed that we were ready for RCTs to prove these hypotheses.

The trials that used this paradigm first were DIAS and DEDAS, to parallel studies in which desmoteplase, a fibrinolytic enzyme from the saliva of the Desmodes rotun$d u s$ bat, in a time window of 3-9 h was studied. Numerous colleagues from North America and Europe were involved in this program, including Albers Greg, Toni Davalos, Marc Fischer, Toni Furlan, Markku Kaste, Ken Lees, Wolfgang and Mariola Soehngen, and Steve Warach. In DIAS, increased hemorrhage rates were observed with high, fixed doses of desmoteplase in the first part of the trial. The protocol was modified accordingly and DIAS part 2 included 57 patients randomized to weight-adjusted doses escalating through $62.5,90$ and $125 \mu \mathrm{g} / \mathrm{kg}$ or placebo. The safety end point was the rate of sICH. Efficacy end points were the rate of reperfusion on MRI after 4$8 \mathrm{~h}$ and clinical outcome as assessed by NIHSS, mRS, and $\mathrm{BI}$ at 90 days. The sICH rates were $2.2 \%$. Reperfusion rates up to $71.4 \%(\mathrm{p}=0.0012)$ were observed with desmoteplase $(125 \mu \mathrm{g} / \mathrm{kg})$ compared with $19.2 \%$ with placebo. Early reperfusion correlated favorably with clinical outcome $(\mathrm{p}=0.0028)$. Favorable outcome occurred in $52.5 \%$ of patients experiencing reperfusion versus $24.6 \%$ of patients without reperfusion [21].

DEDAS [22], the parallel trial performed in the USA, included 37 patients who were randomized and received 2 doses of desmoteplase versus ITT (placebo: $\mathrm{n}=8 ; 90 \mu \mathrm{g}$ / $\mathrm{kg}: \mathrm{n}=14 ; 125 \mu \mathrm{g} / \mathrm{kg}: \mathrm{n}=15)$. No symptomatic intracranial hemorrhage occurred. Treatment with intravenous desmoteplase 3-9 h after ischemic stroke onset appeared safe and at a dose of $125 \mu \mathrm{g} / \mathrm{kg}$ desmoteplase appeared to improve clinical outcome.

The time seemed to be right for the pivotal phase III trial, and we designed DIAS II, an RCT that included patients with AIS and tissue at risk assessed by either MRI or CT imaging. They were randomly assigned (1:1:1) to 2 
doses of desmoteplase or placebo within 3-9 h after the onset of symptoms of stroke [23].

Almost 200 patients were included; 158 patients completed the study. The median baseline NIHSS score was 9 points. Thirty percent (53 of 179) of the patients had a visible occlusion of a vessel at presentation. The core lesion and the mismatch volumes were small (median volumes were 10.6 and $52.5 \mathrm{~cm}^{3}$, respectively). The results were very disappointing: The clinical response rates at day 90 were $47 \%$ (27 of 57) for $90 \mu \mathrm{g} / \mathrm{kg}$ desmoteplase, $36 \%$ (24 of 66) for $125 \mu \mathrm{g} / \mathrm{kg}$ desmoteplase, and 46\% (29 of 63) for placebo. The DIAS-2 study did not show a benefit of desmoteplase given 3-9 h after the onset of stroke. The high response rate in the placebo group was explained by the mild strokes (low baseline NIHSS scores, small core lesions, and small mismatch volumes that were associated with no vessel occlusions), which possibly reduced the potential to detect any effect of desmoteplase. It also raised concerns about the validity of mismatch selection, despite further encouraging trials such as EPITHET and the DEFUSE studies.

\section{Malignant MCA}

The Decompressive Surgery Trials

Despite the striking effects on mortality, decompressive surgery for malignant MCA infarction was still emotionally discussed. The fear was that survival would be associated with poor clinical outcome prevailed. Although it seemed difficult to perform randomized trials with such a big difference in mortality to be expected, RCTs were launched in many parts of the world. Three of the trials were performed in Holland, France and Germany. Like expected all suffered from low recruitment rates. The French trial was stopped by the safety board because of a significant difference in mortality (which was not the end point to be tested). Before the outcome data were unblinded and while the 2 other trials were still running, the principal investigators of DESTINY, DECIMAL and HAMLET, among them Marie-Germain Bousser, Katayoun Vahedi, Eric Juettler, Bart van der Worp, Ale Algra and Jeanette Hofmeijer, decided to pool their blinded data and give them to Peter Rothwell and coworkers in Oxford. The trials differed in several details (stroke severity, time to surgery, imaging criteria, end points), and a new trial design for the joint analysis was prospectively agreed upon.

The final analysis [24] included all patients from DECIMAL and DESTINY and 23 patients from HAMLET who fullfilled the new protocol criteria. A total of $93 \mathrm{pa}-$ tients 60 years or younger, who were treated within $48 \mathrm{~h}$ after symptom onset ( 51 treated by hemicraniectomy and 42 treated conservatively) were included. The primary outcome measure was the mRS at 1 year dichotomized between favorable (0-4) and unfavorable $(5,6)$. Secondary outcome measures included case fatality rate at 1 year and a dichotomization of the mRS between $0-3$ and 4-6.

Mortality at 1 year was significantly decreased from $71.4 \%$ in the conservative group to $21.6 \%$ in the surgery group (absolute risk reduction $49.8 \%$ ). More patients in the surgery group had an mRS score $\leq 4$ (74.5 vs. $23.8 \%$ ) and an $\mathrm{mRS}$ score $\leq 3$ (43.1 vs. $21.4 \%$ ). The severest disability (mRS score 5 ) was not increased (4 vs. $5 \%$ ). The effect of surgery was highly consistent across the three trials.

We concluded that in younger patients with malignant MCA infarction, decompressive surgery undertaken within $48 \mathrm{~h}$ of stroke onset reduces mortality and increases the number of patients with a favorable functional outcome. This pooled analysis forms the basis of most current guidelines and recommendations for acute stroke treatment concerning surgical treatment of malignant MCA infarction

\section{DESTINY II Results}

The pooled analysis results apply for patients 60 years or younger, irrespective of the hemisphere involved. So far there were no data from randomized trials on patients older than 60 years. To further assess the question of how to treat older patients with malignant MCA infarction, DESTINY II was designed [25]. The inclusion time remained at $48 \mathrm{~h}$. Patients 61 years or older with the clinical and radiographic criteria of a malignant MCA infarction were randomized to surgery or conservative ICU treatment. The statistical protocol recommended study termination once the primary end point (mRS $0-4$ vs. 5, 6 at 6 months) was statistically significantly different.

The results of DESTINY II were just presented [26] and publication is under review.

The termination of the study was based on the 6-month results of 82 patients. As expected, the overall outcome in this elderly population (mean age 70 years, initial NIHSS mean $>21$ ) is worse than in patients under 60 years old. Nevertheless, for the primary end point dichotomized at $0-4$ vs. 5,6 (39\% surgery vs. $17 \%$ conservative, absolute risk reduction 22\%) and the shift analysis, the results are clearly in favor of surgery. The difference in mortality is almost $40 \%$. Compared with younger patients undergoing surgery, the rate of survivors with an mRS of 5 is higher, reflecting the worse overall outcome of elderly stroke patients. 
The definition of favorable and unfavorable outcomes in a condition with such a high mortality rate under conservative treatment is under dispute. It may be questioned as to whether the terms 'favorable' and 'unfavorable' should be replaced by 'acceptable' and 'inacceptable'. To answer this question, more data on the quality of life of patients after malignant MCA infarction are needed. DESTINY II will also report data on patients and caregivers' views of outcome achieved and retrospective consenting to the study.

\section{Final Conclusions}

I had good times and bad times during my years in the field of acute stroke treatment and critical care of stroke. I left out several other trials (mostly with negative results, such as ASTIN, AbESTT II or the transcranial laser therapy development, i.e. the NEST studies), which culminated in my presentation of the futile results of NEST III at the London European Stroke Conference meeting. I also did not reflect on the development of hyperacute stroke units, a process that started in Germany, triggered by the activities of good friends such as Michael Hennerici, Christoph Diener, Bernd Ringelstein, Otto Busse, Peter Ringleb and Martin Grond, just to name a few. And since my topic was acute stroke treatment, the field of prevention [antithrombotics (CAPRIE, CHARISMA, ROCKET-AF) and carotid surgery and stenting (SPACE, SPACE II)] has been left out.
Overall, my experience was a pleasant one, and many colleagues and friends I met during these years have enriched my life. I am pleased to see that at least some of the results we produced made their way into guidelines and may have changed the way we approach acute stroke and neurology.

\section{Acknowledgments}

In addition to all the colleagues already mentioned in the text, I would like to thank my colleagues who worked with me in Heidelberg: K. Kunze, R. v. Kummer, D. Krieger, K. Sartor, A. Aschoff, A. Grau, M. Spranger, M. Forsting, V. Schuchardt, K. Rieke, S. Schwab, M. Knauth, T. Brandt, M. DiGeorgia, E. Keller, T. Steiner, P. Ringleb, O. Jansen, W. Schäbitz, P. Schellinger, J. Fiebach, A. Unterberg, R. Veltkamp, A. Rocco, E. Jüttler, C. Lichy, S. Nagel, J. Bösel, M. Bendszus, M. Hartmann, S. Hähnel, S. Poli, M. Sykora, J. Diedler.

\section{Disclosure Statement}

I received financial compensation for work in the steering committees of large clinical trials such as ECASS 1-3 (Boehringer Ingelheim), AbESTT (Lilly), DIAS, DEDAS, DIAS II (PAION); NEST 2 and 3 (PHOTOTHERA). I have also received consulting honoraria and speaker fees from the above-mentioned companies. DESTINY II was supported by the German Research Foundation and the German Ministry of Science and Education (JU 2764/1-1).

\section{References}

1 Zeumer H, Hacke W, Kolmann HL, Poeck K: Lokale Fibrinolyse bei Basilaristhrombose. Dtsch Med Wochenschr 1982;107:728-731.

-2 Zeumer H, Hacke W, Ringelstein EB: Local intraarterial thrombolysis in vertebrobasilar thromboembolic disease. AJNR Am J Neuroradiol 1983;4:401-404.

-3 Zeumer H, Hundgen R, Ferbert A Ringelstein EB: Local intraarterial fibrinolysis in inaccessable internal carotid occlusion. Neuroradiology 1984;26:315-317.

4 Hacke W, Zeumer H, Ferbert A, Brückmann $\mathrm{H}$, Del Zoppo: Intraarterial thrombolytic therapy improves outcome of patients with acute vertebro-basilar occlusive disease. Stroke 1988;10:1216-1222.

5 Del Zoppo GJ, Ferbert A, Otis S, Brueckmann H, Hacke W, Zyroff J, Harker LA, Zeumer H: Local intra-arterial fibrinolytic therapy in acute carotid artery stroke. Stroke 1988;19: 307-313.
6 Del Zoppo GJ, Poeck K, Pessin M, Wolpert SA, Furlan AJ, Ferbert A, Zivin J, Wechseler L, Busse O, Mohr JP, Hacke W, Kase CS, Biller J, Otis SM: Recombinant tissue plasminogen activator in acute thrombotic and embolic stroke Ann Neurol 1992;32:78-86.

7 Von Kummer R, Hacke W: Safety and efficacy of intravenous tissue plasminogen activator and heparin in acute middle cerebral artery stroke. Stroke 1992;23:646-652.

8 Hacke W, Kaste M, Fieschi C, et al: Intravenous thrombolysis with recombinant tissue plasminogen activator for acute hemispheric stroke. The European Cooperative Acute Stroke Study (ECASS). JAMA 1995;274: 1017-1025.

$\checkmark 9$ The National Institute of Neurological Disorders and Stroke rt-PA Stroke Study Group: Tissue plasminogen activator for acute ischemic stroke. N Engl J Med 1995;333:15811587.
10 Hacke W, Bluhmki E, Steiner T, Tatisumak T, Mahagne MH, Sacchetti ML, Meier D: Dichotomized efficacy and global endpoint analysis of the ECASS 1 ITT data set. Stroke 1998;29:2073-2075.

11 Hacke W, Kaste M, Fieschi C, von Kummer R, Davalos A, Meier D, Larrue V, Bluhmki E, Davis S, Donnan G, Scheider D, Diez-Tejedor E, Trouilas P: Randomised double-blind placebo-controlled trial of thrombolytic therapy with intravenous alteplase in acute ischaemic stroke (ECASS II). Lancet 1998;352:12451251.

12 Hacke W, Schwab S, Horn M, Spranger M, De Georgia M, von Kummer R: 'Malignant' middle cerebral artery territory infarction: clinical course and prognostic signs. Arch Neurol 1996;53:309-315. 
13 Rieke K, Schwab S, Krieger D, von Kummer R, Aschoff A, Schuchardt V, Hacke W: Decompressive surgery in space-occupying hemispheric infarction. Crit Care Med 1995; 23:1576-1587.

14 Forsting M, Reith W, Schabitz WR: Decompressive craniectomy for cerebral infarction. An experimental study in rats. Stroke 1995; 26:259-264.

15 Schwab S, Steiner T, Aschoff A, Schwarz S, Steiner HH, Jansen O, Hacke W: Early hemicraniectomy in patients with complete middle cerebral artery infarction. Stroke 1998;29: 1888-1893.

- 16 Schwab S, Schwarz S, Spranger M, Keller E, Bertram M, Hacke W: Moderate hypothermia in the treatment of patients with severe middle cerebral artery infarction. Stroke 1998;29: 2461-2466.

17 Hacke W, Donnan G, Fieschi C, von Kummer R, Davalos A, Meier D, Larrue V, Bluhmki E, Davis S, Donnan G, Schneider D, Diez-Tejedor E, Troullias P: Association of outcome with early stroke treatment: pooled analysis of ATLANTIS, ECASS, and NINDS rt-PA stroke trials. Lancet 2004;363:768774 .
18 Lees KR, Bluhmki E, von Kummer R, Brott TG, Toni D, Grotta JC, Albers GW, Kaste M, Marler JR, Hamilton SA, Tilley BC, Davis SM, Donnan GA, Hacke W: Time to treatment with intravenous alteplase and outcome in stroke: an updated pooled analysis of the ECASS, ATLANTIS, NINDS, and EPITHET trials. Lancet 2010;375:1695-1703.

19 Hacke W, Kaste M, Bluhmki E, Brozman M, Davalos A, Guidetti D, Larrue V, Lees KR, Medeghri Z, Machnig T, Schneider D, von Kummer R, Wahlgren N, Toni D, ECASS Investigators: Thrombolysis with alteplase 3 to $4.5 \mathrm{~h}$ after acute ischemic stroke. $\mathrm{N}$ Engl J Med 2008;359:1317-1329.

20 Jansen O, Schellinger P, Fiebach J, Hacke W, Sartor K: Early recanalisation in acute ischaemic stroke saves tissue at risk defined by MRI. Lancet 1999;353:2036-2037.

21 Hacke W, Albers G, Al-Rawi Y, Bogousslavsky J, Davalos A, Eliasziw M, Fischer M, Furlan A, Kaste M, Lees KR, Soehngen M, Warach S: The Desmoteplase in Acute Ischemic Stroke Trial (DIAS): a phase II MRI-based 9-hour window acute stroke thrombolysis trial with intravenous desmoteplase. Stroke 2005;36: 66-73.
22 Furlan AJ, Eyding D, Albers GW, Al-Rawi Y, Lees KR, Rowley HA, Sachara C, Soehngen M, Warach S, Hacke W: Dose Escalation of Desmoteplase for Acute Ischemic Stroke (DEDAS): evidence of safety and efficacy 3 to $9 \mathrm{~h}$ after stroke onset. Stroke 2006;37:12271231.

23 Hacke W, Furlan AJ, Al-Rawi Y, Davalos A, Fiebach JB, Gruber F, Kaste M, Ringleb P, Rowley HA, Schneider D, Schwamm L, Soehngen M, Wilhelm-Oyungbini K, Wintermark M, Warach S: Intravenous desmoteplase in patients with acute ischaemic stroke selected by MRI perfusion-diffusion weighted imaging or perfusion CT (DIAS-2): a prospective, randomised, double-blind, placebo-controlled study. Lancet Neurol 2009;8:141-150.

24 Vahedi K, Hofmeijer J, Juettler E, Vicaut E, George B, Algra A, Amelink GJ, Schmiedeck P, Schwab S, Rothwell PM, Hacke W: Early decompressive surgery in malignant infarction of the middle cerebral artery: a pooled analysis of three randomized controlled trials. Lancet Neurol 2007;3:215-222.

25 Juttler E, Bösel J, Amiri H, Schiller P, Limprecht R, Hacke W, Unterberg A: DESTINY II: DEcompressive Surgery for the Treatment of malignant INfarction of the middle cerebral arterY II. Int J Stroke 2011;6:79-86.

26 Hacke W: DESTINY II results oral presentation. ESC, London, 2013.
Good Times - Bad Times: My Story regarding Acute Stroke Treatment 